\title{
AS PERCEPÇÕES DE DOENÇA MENTAL NA ÓTICA DE FAMILIARES DE PESSOAS PSICÓTICAS ${ }^{1}$
}

\author{
MENTAL DISEASE PERCEPTIONS FOR PSYCHOTIC PEOPLE RELATIVES \\ LA CONCEPCIÓN DE ENFERMEDAD MENTAL PARA LOS PARIENTES DE PERSONAS SICÓPATA
}

\section{Tarciana Raquel Moraski ${ }^{2}$, Leila Mariza Hildebrandt ${ }^{3}$}

RESUMO: Este estudo teve como objetivo conhecer a concepção dos familiares de pessoas portadoras de psicose, sobre doença mental. Para o alcance destes objetivos, lançamos mão da investigação de abordagem qualitativa, descritiva, exploratória, do tipo estudo de caso. Os sujeitos do estudo foram seis familiares de pessoas acometidas por transtornos mentais psicóticos, assistidas na Unidade Hospitalar ou residindo na Moradia Terapêutica do Instituto Cyro Martins de Porto Alegre/RS. Para a coleta de dados, realizamos contato com os familiares via telefônica ou pessoalmente, no horário de visitação aos internados. $\mathrm{Na}$ medida que os mesmos aceitaram fazer parte da pesquisa, marcou-se horário e local para realização da entrevista. Para a obtenção dos dados, utilizamos a entrevista semi-estruturada, cujos depoimentos foram gravados e transcritos na íntegra. Também foi utilizado o diário de campo para o registro de informações não captáveis pelo gravador, bem como percepções do entrevistador durante a realização da entrevista. Para a análise dos dados, utilizamos a proposta metodológica de MINAYO (2001), constituída por ordenação e classificação dos dados e análise final. O projeto de pesquisa foi aprovado pelo Comitê de Ética na Universidade Regional do Noroeste do estado do Rio Grande do Sul. Mediante a leitura do material coletado no campo empírico da pesquisa, as informações foram agrupadas em uma categoria de análise abordando a concepção de doença mental, considerando a similaridade e diversidade das informações obtidas. Os depoentes se posicionaram caracterizando a doença mental como uma patologia opressora, capaz de causar impotência, como um transtorno da cabeça; uma patologia que abala as estruturas familiares, um mal endógeno; um mal dos nervos; um problema de caráter social; como sinônimo de incapacidade e como uma doença que provoca desrealização e despersonalização. A partir desta investigação, percebemos a importância de assistir os familiares que acompanham o doente mental psicótico, durante o seu tratamento.

PALAVRAS CHAVES: Concepção; Transtornos Mentais; Percepção Social; Família.

ABSTRACT: This study had the objective knows the people's psychosis bearers relatives' conception, on mental disease. It goes the reach of these objectives, we threw hand of the investigation of approach qualitative, descriptive, exploratory, of the type marries study. The subject of the study were six family of people attacked by psychotic mental upset, attended in the Unit Hospitalar or residing in the Therapeutic Home of Porto Alegre/RS's Instituto Cyro Martins. It goes the collection of it dates, we accomplished contact with the relatives phone road or personally, in the schedule of visitation to those interned. In the measure that the same ones accepted to of the part of the research, it was marked schedule and place goes accomplishment of the interview. It goes the obtaining of the it dates, we used the semi-structured interview, whose depositions were recorded and transcribed in the completes. The field diary was also used goes the registration of information you didn't it captures it goes the it closes recorder, the well the the interviewer's perceptions during the accomplishment of the interview. It goes the analysis of the it dates, we used the methodological proposal of MINAYO (2001), constituted by ordination and classification of the dates and final analysis. The research project was approved by the Committee of Ethics in Regional the University of the Northwest of the state of Rio Grande do Sul. By the reading of the material collected in the empiric field of the research, the information were contained in an analysis category approaching the conception of mental disease, considering the similarity and diversity of the obtained information. The depoentes were positioned characterizing the mental disease the the pathology opressora, capable to causes impotence, the an upset of the head; the pathology that affects the family structures, an endogenous evil; the badly of the nerves; the problem of social character; the synonym of incapacity and the the disease that provokes desrealização and despersonalização.

1 Artigo elaborado a partir do Trabalho de Conclusão de Curso de Enfermagem intitulado "A concepção de doença mental e a vivência na agudização dos sintomas na voz de familiares de pessoas psicóticas", apresentado no primeiro semestre de 2005, na Universidade Regional do Noroeste do Estado do Rio Grande do Sul (UNIJUí).

2 Graduada em Enfermagem pela Universidade Regional do Noroeste do Estado do Rio Grande do Sul - UNIJUÍ. Membro do Grupo de Estudos Educação e Pesquisa em Saúde - GEPES/DCSA/UNIJUí. E-mail: tarci.raquel@ibest.com.br. Endereço: Rua Dr.Pestana, 1021, centro, CEP: 98700 - 000, IJUí/RS.

3 Enfermeira, Mestre em Enfermagem Psiquiátrica pela EERP/USP, Docente do Departamento de Ciências da Saúde (DCSa) da Universidade Regional do Noroeste do Estado do Rio Grande do Sul (UNIJUÍ), Coordenadora do Grupo de Estudos em Saúde Mental e Gerontologia do DCSA/UNIJUÍ. E-mail: leilah@unijui.tche.br. Endereço: Rua dos Carajás, 82, CEP:98700-000, IJUí/RS. 
Starting from this investigation, we noticed the importance of attending the relatives that accompany the psychotic mental patient, during your treatment.

KEYWORDS: Conception; Mental disease; Family; Psychosis.

RESUMEN: Este estudio tuvo como objetivo conocer la concepción de los parientes de portadores de psicosis de las personas, en la enfermedad mental. Para el alcance de estos objetivos, nosotros tiramos mano de la investigación de acercamiento cualitativo, descriptivo, exploratorio, del tipo el estudio del caso. El asunto del estudio fueron seis familiares de las personas atacadas por enfermeda mental del psicópata perturbada, asistidos en la Unidad Hospitalar o residiendo en la Casa Terapéutica del Instituto Cyro Martins de Porto Alegre/RS. Para la colección de datos, nosotros logramos el contacto con los parientes por teléfone el camino o personalmente, en el horario de visita a aquéllos internados. En la medida que los mismos aceptaron hacer parte de la investigación, era el marcado horario y el lugar para lograr la entrevista. Para obtener el datos, nosotros usamos la entrevista semi-estructurada cuya deposiciones se grabaron y transcribieron completamente. El diario del campo también fue usado para registro de información que no fue capturada por el registrador, bien como las

\section{INTRODUÇÃO}

Trabalhar com o tema família e doença mental nasceu no âmago de uma inquietação acadêmica, quando nos deparamos com cidadãos portadores de psicopatologias crônicas, considerados pela sociedade em geral com o estereótipo de "loucos". Ao conviver com esse contingente populacional, percebemos que estes sujeitos, para além de serem portadores de um transtorno mental grave, eram movidos por sentimentos, por afeto, carentes de inter-relação pessoal, de cuidado, de aproximação, de vínculo e, principalmente, de vida. Esta situação mobilizou-nos, aguçando um forte desejo de saber mais sobre eles e principalmente compreender $\mathrm{e}$ identificar as representações construídas por seus familiares a respeito do fenômeno doença mental, principalmente diante das transformações paradigmáticas que estão a orientar o campo da saúde mental na atualidade.

Entendemos família como um grupo, capaz de interagir entre si e de compartilhar significados de suas experiências existenciais, constituindo-se no alicerce da sociedade. Cada família traz em si uma história de vida, de valores, de crenças, de conceitos e culturas, perpetuados ao longo de sua trajetória social. Neste bojo, em toda instituição familiar se perpetua a idéia de que sua linhagem genética deve ser saudável, preparada para assumir papéis sociais e o mercado de percepciones del entrevistador durante el logro de la entrevista. Para el análisis de datos, nosotros usamos la propuesta metodológica de MINAYO (2001), constituída por la ordenación y clasificación de los datos y último análisis. El proyecto de la investigación fue aceptado por el Comité de Ética en Regional la Universidad del Noroeste del Estado de Río Grande del Sul. Por la lectura del material colectado en el campo empírico de la investigación, las información es fueron agrupadas en una categoría del análisis que se acerca la concepción de enfermedad mental, considerado la similitud y diversidad de las informaciónes obtenidas. Los depoentes se posicionaron caracterizando la enfermedad mental como una patología opressora, capaz de causar impotencia, como un trastorno de la cabeza; una patología que afecta las estructuras familiares, un mal endógeno,; un mal de los nervios; un problema de carácter social; como sinónimo de incapacidad y como enfermedad que provoca desrealizacion $y$ despersonalizacion. A partir de esta investigación, nosotros notamos la importancia de asistir a los parientes que acompañan al paciente mental sicópata, durante su tratamiento.

PALABRAS CLAVES: La concepción; La enfermedad mental; La familia; La psicosis.

trabalho. Ao ver frustrado esses papéis, tendo que assumir a responsabilidade de cuidar de um filho "anormal", diferente do ideal para que foi criado, uma série de respostas são evidenciadas, desde a anuência da doença até a completa negação e não aceitação desta vivência. Em contrapartida, os sentimentos manifestados e as concepções que permeiam o âmbito familiar em relação à doença mental são revestidos de uma tendência hegemônica, face às múltiplas representações da doença mental apresentados ao longo do tempo.

Considerando a trajetória histórica percorrida pela Saúde Mental, notamos que, em vários momentos, os indivíduos de conduta desviante ou considerado indesejáveis pela comunidade, representavam medo, perigo, ameaça e desonra para a família e à sociedade, sendo, por isso, excluídos de seu convívio familiar e isolados em locais próprios para eles, os manicômios. Esses sentimentos embora não tão aparentes como outrora, devido à nova concepção da doença mental, continuam presentes até os dias atuais. Assim, mesmo diante de um novo paradigma de intervenção sobre patologias mentais, esta ainda continua sendo vista com preconceito e estigma, não só pela comunidade em geral, mas também pela própria família do doente.

Muitas famílias ainda não conseguiram assimilar a doença mental em seu real sentido que, alicerçado 
em TOWNSEND (2002, p. 15), significa "respostas desajustadas a fatores de estresse do ambiente interno ou externo, evidenciadas por pensamentos, sentimentos e comportamentos que não são congruentes com as normas locais e culturais e interferem no funcionamento social, ocupacional e/ou físico do indivíduo". Corroborando, STUART \& LARAIA (2001) pontuam que a psicose é entendida como uma síndrome caracterizada pela perda do teste de realidade e sobre a percepção de si mesmo, de tal maneira que se torna difícil discernir a ligação com a realidade presente, surgindo delírios e alucinações de ordem variadas, refletindo-se na forma de agir e proceder dessas pessoas. Por sua vez, a saúde mental é sinônimo de equilíbrio, representada pela capacidade da pessoa adaptar-se ao meio social ao qual está inserido (BERTOLLO, 2003). Perpassando o aspecto social, esse equilíbrio deve abranger os aspectos biológicos, psicológico, político, econômico, cultural, ocupacional e espiritual, enfim, deve haver uma estabilidade entre os fatores internos e externos que poderiam estar contribuindo para a saúde mental da pessoa. Na medida que houver desequilíbrio em uma ou nas mais diversas áreas que compõe o cotidiano do indivíduo, poderá ocorrer o desencadeamento de transtorno mental, visto e interpretado de formas distintas pelo contexto antropológico bio-cultural.

Neste ínterim, a História da Loucura pode ser caracterizada por um conjunto de acontecimentos em constantes transformações, que contextualizam os desafios que a constituem e as superações que já se efetivaram no seu decurso. Entre essas superações merece destaque a Reforma Psiquiátrica, movimento que visa a transformação do paradigma tradicional da psiquiatria e a elaboração de propostas apontando para a desinstitucionalização do doente mental e a inserção da família como coadjuvante no processo terapêutico do sujeito doente mental. No entanto, muitas famílias não estão preparadas para enfrentar os desafios sociais e a complexidade de demandas impostas pela doença mental. Esses familiares estão inseridos em um contexto social que, ainda, se mostra resistente em aceitar o transtorno psiquiátrico como uma situação que pode fazer parte do processo existencial da humanidade. A sociedade, e aí se inclui a família, por vezes impregnada pelos conceitos clássicos de loucura, ou seja, dos conceitos de incapacidade, de incurabilidade, periculosidade e irreversibilidade da doença, potencializa as limitações da pessoa acometida por um distúrbio desta ordem.

Em virtude da necessidade de se (re) conhecer o doente mental como um cidadão, com direitos e deveres, sem desconhecer as particularidades inerentes à psicose, nasceu esta inquietação, que se constitui no nosso objeto de estudo: como os familiares de doentes mentais psicóticos concebem a doença mental? Como pressuposto da pesquisa usamos o atributo de que o doente mental psicótico pode ainda hoje ser visto como um "louco" pelos seus familiares, e encarado como objeto de perturbações ditas como incuráveis, responsáveis por perturbações anti-sociais, principalmente quando estes enfrentam a manifestação dos sintomas agudos da doença, com comportamentos seriamente conturbados e condutas estranhas que, por vezes, impressionam e causam temor aos sujeitos envolvidos no processo, dependendo da forma de se conceber e enfrentar a situação.

Considerando o exposto, este estudo tem como objetivo conhecer a concepção dos familiares sobre doença mental.

\section{METODOLOGIA}

Considerando o caráter de nossa investigação, nosso objeto de estudo e nossos objetivos, direcionamos a construção deste trabalho dentro da abordagem qualitativa, descritiva, exploratória, do tipo estudo de caso, por considerarmos a adequação desta as nossas aspirações. O estudo foi realizado no município de Porto Alegre, capital do Estado do Rio Grande do Sul, junto ao Instituto Cyro Martins. Para MINAYO (2001), a pesquisa qualitativa responde a questões muito particulares relativas às ciências sociais, ou seja, coloca como tarefa central a compreensão da realidade humana vivida socialmente. O estudo descritivo, segundo GIL (1999), tem como objetivo principal descrever características de determinada população ou fenômeno, bem como o estabelecimento de relações entre variáveis. O presente estudo ainda é classificado como exploratório pois, conforme o mesmo autor, este tipo de estudo tem como principal finalidade desenvolver, esclarecer e modificar conceitos e idéias, tendo em vista, a formulação de problemas mais precisos ou hipóteses pesquisáveis para estudos posteriores. TRIVINOS (1999) corrobora afirmando que o estudo de caso tem como objetivo o estudo profundo e exaustivo de objetos, de maneira a permitir o seu conhecimento amplo e detalhado.

Porto Alegre pode ser considerada como referência na área da psiquiatria dentro do estado do Rio Grande do Sul, por contar com uma vasta rede especializada que atende pessoas portadoras de sofrimento psíquico. Instituto Cyro Martins é o nome fantasia dado a duas instituições interligadas que, conjuntamente, se dedicam a atenção na área da saúde mental em Porto Alegre, dentro de uma mesma filosofia de tratamento: Centro Clínico Três Figueiras que é a razão social da Unidade Hospitalar (local de nosso estudo) e Centro Clínico Petrópolis que abrange as unidades ambulatoriais e de ensino vinculadas a Unidade Hospitalar (INSTITUTO CYRO MARTINS, 2004). Esta instituição faz parte do novo modelo de assistência preconizado pela reforma psiquiátrica, para onde o sujeito é levado até atingir sua reabilitação e, conseqüentemente, reinserção familiar e social, em 
que completará seu tratamento, auxiliado pelos serviços de contra-referência que poderá ser um CAPS (Centro de Atenção Psicossocial) e/ou outros serviços substitutivos. A organização Cyro Martins ainda oferece uma modalidade de serviço substitutivo, denominada de Moradia Terapêutica, para onde são encaminhados os indivíduos em estados crônicos de patologias psiquiátricas, com poucas condições de retornarem a seus lares e vínculos sociais.

Os sujeitos do estudo foram seis familiares de doentes mentais psicóticos vinculados ao Instituto Cyro Martins da cidade de Porto Alegre/RS. Para ajudar a delinear o perfil dos sujeitos da pesquisa, optamos por escolher como depoentes, familiares dos doentes internados na Unidade Hospitalar e/ou residentes na Moradia Terapêutica. Estes familiares acompanhavam e participavam assiduamente do tratamento realizado pelo usuário. Caracterizando: três mães, dois pais e uma tia, com idades variando entre 45 e 70 anos e escolaridade do Ensino Médio ao superior. Os entrevistados possuíam uma certa homogeneidade no que se refere à posição social e econômica, pertencendo a classe média/alta. Em relação ao diagnóstico da patologia do familiar doente, que se encontrava hospitalizado, todos os entrevistados demonstraram saber que há um distúrbio de ordem cognitiva, comportamental envolvendo o familiar, porém apenas um depoente se mostrou preciso na questão de atribuir um nome específico a doença. Quanto ao fator tempo de convívio com o doente mental, percebemos uma dicotomia, pois cinco dos entrevistados convivem com seu familiar doente mental há mais de 15 anos, enquanto apenas um caso é mais recente, em que a doença havia se manifestado há aproximadamente dois meses. Respeitando os preceitos éticos, os depoentes foram identificados com o pseudônimo de sentimentos e atitudes, dado a relação de harmonia, de afetividade e de vínculo com que cuidavam de seu familiar internado. Desta forma, os participantes da pesquisa foram denominados respectivamente de $A M O R$, AFETO, CARINHO, TERNURA, AFAGO e DEDICAÇÃO.

A coleta de dados foi realizada por meio de entrevista semi-estruturada, gravada em áudio-tape e logo depois transcrita na íntegra. Durante a entrevista, também utilizamos como fonte de dados a observação assistemática com registro em diário de campo. O instrumento de coleta de dados utilizado para efetivar a entrevista semi-estruturada foi composto por duas partes, em que a primeira teve por objetivo levantar os dados de identificação e de caracterização de nossos atores sociais. A segunda etapa teve por objetivo levantar a percepção dos familiares sobre a doença mental de seu ente querido. O presente artigo vem apresentar os dados obtidos por meio da entrevista e também àqueles obtidos pelas observações registradas em diário de campo.
Todo o processo investigatório foi realizado mediante conhecimento de nossos objetivos, pelos responsáveis pela área de pesquisa do Instituto Cyro Martins, bem como concordância e assinatura de termo de consentimento livre e esclarecido, pelos depoentes, conforme preconiza a Resolução 196/96 do Conselho Nacional de Saúde do Ministério da Saúde (BRASIL, 1996). O projeto de pesquisa foi aprovado pelo Comitê de Ética em Pesquisa da Universidade Regional do Noroeste do Estado do Rio Grande do Sul (UNIJUÍ) mediante o protocolo de pesquisa $n^{\circ}$ 012/2005 de 07/03/2005.

A análise dos dados seguiu os passos metodológicos propostos por MINAYO (2001), quais sejam: ordenação, classificação e análise final dos dados. Na ordenação dos dados, organizamos todo o material obtido durante o trabalho de campo, realizando a transcrição e leitura das entrevistas, ordenando as anotações feitas no diário de campo e organizando os relatos dos participantes. A fase da classificação dos dados foi construída a partir de questionamentos realizados sobre estes dados, baseado na fundamentação teórica e releitura do material coletado. A partir disso, foi elaborado as categorias empíricas do estudo. A análise final constituiu-se no estabelecimento de articulações entre os dados da pesquisa e os referenciais teóricos abordados, respondendo a questão da pesquisa com base no objetivo do estudo. De posse do material coletado, passamos, no momento, a realizar a apresentação e análise das informações obtidas junto aos atores sociais do estudo.

\section{APRESENTAÇÃO E DISCUSSÃO DOS RESULTADOS}

Mediante a leitura do material coletado no campo empírico da pesquisa, as informações foram agrupadas em uma categoria de análise, a qual aborda a concepção de doença mental, considerando a similaridade e diversidade das informações obtidas. Denotamos um certo grau de ambigüidade e sobreposição de conceitos dos familiares a respeito da definição e compreensão da doença mental, face ao convivido prolongado de alguns familiares com 0 transtorno, enquanto que outros conviveram por um tempo menor.

\section{CATEGORIA: A CONCEPÇÃO DE DOENÇA MENTAL NA ÓTICA DE FAMILIARES DE PESSOAS COM TRANSTONOS PSICÓTICOS QUE SE ENCONTRAM HOSPITALIZADAS}

Por meio dos relatos que, a partir de agora, serão apresentados percebemos que as pessoas vão constituindo, ao longo do tempo, suas concepções a respeito da doença bem como as formas de tratá-la. Essas concepções, muitas vezes, perpassam os 
aspectos nosológicos, atribuindo conceitos próprios, adquiridos pela vivência com a doença e o doente.

Para alguns dos participantes do estudo a doença mental é vista como uma patologia opressora, capaz de causar impotência. O trecho da entrevista selecionado a seguir ilustra essa forma de perceber a doença mental:

“... a doença mental é uma doença como outra qualquer, só que a mental é mais opressora. É uma doença que oprime muito o paciente, ele sabe que está doente, ele tem essa consciência, mas ele não pode, ele é impotente, face às coisas que ocorre com ele" (AMOR).

Conforme KOGA \& FUREGATO (1998), a vida do doente mental vai sendo degradada pelo diagnóstico de patologia mental e especialmente pelos tratamentos a que ele é submetido. Consideramos que esses fatores geram opressão no doente mental que não consegue, com suas próprias forças, combater e/ou sair da condição que Ihes foi imposta pela enfermidade.

A loucura normalmente não absorve todos os aspectos da vida da pessoa. Apenas algumas funções da vida mental são atingidas, o que permite ao doente mental conservar a consciência de si mesmo, do mundo e do que faz, embora possa estar, por vezes, desorientado. Ao conservar a consciência de si mesmo, do mundo e daquilo que faz, o doente mental é capaz de desencadear e vivenciar um estresse muito grande ao ter a noção de seu real estado, que resultam em impotência e vulnerabilidade em não poder vencer a doença. Esta fragilidade aparece, muitas vezes, no descontrole da situação, assumindo a forma de tristeza, irritação, confusão e instabilidade emocional. O relato a seguir evidencia nitidamente o sofrimento e opressão a que o doente mental é submetido:

“... ele até mesmo se auto-agride, de vez em quando ele bate com a cabeça na parede e tal... ele chega a me perguntar porque Deus não ajuda ele" (AMOR).

Ao analisar o depoimento anterior, evidenciamos que a doença mental pode ser expressa num plano de carências e fraquezas. O doente mental, por sua vez, pode ser representado como um indivíduo portador de necessidades especiais e que vivencia situações conflituosas sem conseguir com suas próprias forças resolvê-las. Neste conjunto de respostas é enfatizada a etiologia da doença como conflitos internos e os doentes como pessoas portadoras de transtornos emocionais e psíquicos, ocasionados pela existência de um mal endógeno capaz de tornar qualquer indivíduo impotente diante da situação.

A Doença mental também foi compreendida como sendo qualquer transtorno da cabeça. Esta forma de perceber a patologia psiquiátrica é comum entre a população em geral, que atribuem ao transtorno mental o pseudônimo de "um problema que se localiza na cabeça" e/ou ainda um mau funcionamento ou má formação do cérebro.

Por outro lado, esta condição imposta pela doença implica numa incapacidade de adequadamente suportar as demandas e pressões da vida. Nos depoimentos a seguir percebemos resquícios desta concepção enraizada, uma vez que os relatos apontam para a concepção da doença mental como uma fraqueza do corpo e da mente, evidenciado por meio de dificuldades de aprendizagem, hiperatividade, introversão ou desorganização na infância. Estes sinais e sintomas iniciais, em determinado momento da vida eclodiram, tomando conta do cérebro e impedindo seu pleno funcionamento:

“... desde o princípio eu tinha a concepção de que meu filho não era normal, tendo em vista sua forma de proceder. Sempre foi uma criança hiperativa, não conseguia progredir na escola" (AFETO);

“... na adolescência todos os retardos mentais contribuíram para aumentar seu problema, se ele fosse um adolescente normal talvez não estivesse hoje nesta condição" (AMOR).

Por meio destas referências podemos traçar um paradoxo. De um lado, denotamos nos sujeitos integrantes do estudo a ocorrência do início do processo de adoecer na adolescência, podendo estas falas identificar os sintomas prodrômicos da doença mental, vindo ao encontro aos apanhados de KAPLAN, SADOCK \& GREBB (2003), os quais pontuam que as idades de pico da esquizofrenia são de 15 a 25 anos em homens, sendo que os homens têm início mais precoce do que as mulheres.

Por outro lado, seguindo o raciocínio de MARI et al (1999), percebemos que as imagens apresentadas aproximam-se de um modelo biomédico de transtorno mental, ou seja, na elaboração de um conceito para a patologia que circunscreve um processo disfuncional, localizado em determinado órgão ou parte do corpo, de início precoce, desencadeado por múltiplos fatores e acarretando uma série de incapacitações ou restrições à vida pessoal e social.

Entretanto, os autores acima mencionados pontuam que a causa da esquizofrenia é desconhecida e que, provavelmente, trata-se de uma doença multifatorial, em que estão envolvidos fatores biológicos, genéticos, psicossociais, neuroquímicos, ambientais e de personalidade.

Ainda, TAYLOR (1992) afirma que é improvável que um único acontecimento, de caráter físico ou emocional, seja suficiente para causar a drástica alteração da personalidade vista na esquizofrenia, embora a maioria dos familiares relaciona a causa a um evento particularmente estressante que precedeu o 
aparecimento da doença. Essas idéias são endossadas pelo relato a seguir:

“... ele ficou assim em função da doença de seu pai, ele está com câncer, está muito mal já tem dois anos. Ele está internado e o meu filho ficou cuidando dele por um tempo e logo depois deu essa loucura nele..." (TERNURA)

Desta forma, entendemos que as elaborações constituídas pelos familiares são uma apropriação do conhecimento adquirido na sociedade e pelo contato com os serviços médicos ao longo do processo terapêutico. Assim, denotamos que, muitas vezes, atribuir ao desencadeamento da doença mental causas específicas e a patologia o estereótipo de transtorno da cabeça é menos constrangedor e doloroso do que identificar suas reais causas e/ou denominá-la pelo seu nome científico. Os autores abaixo fortalecem essas percepções ao afirmar que:

"... ao evitar o uso do nome científico para a doença e ao usar denominações mais amplas, o familiar pode estar afastando questão de estigma social, imprimindo um caráter mais benigno à condição ou não confrontando experiências dolorosas e incompreensíveis da convivência estressante com o familiar doente e expectativas de melhora e cura" (MARI et al, 1999, p. 10).

A Doença mental também foi entendida como uma patologia que abala as estruturas familiares. Sabemos que toda doença crônica, seja ela de origem orgânica ou psicológica, afeta seriamente o grupo familiar. Quando se adoece há uma ruptura de suas atividades normais e algumas delas precisam ser desempenhadas por outras pessoas.

Além disso, a pessoa doente, muitas vezes, necessita ser cuidada, face às manifestações de sua patologia. Quando uma doença é de curta duração já é difícil para a família se estruturar e prosseguir em suas tarefas cotidianas. Quando a enfermidade é crônica, então os problemas se multiplicam consideravelmente, sendo necessário ajustes e adaptações.

Muitas vezes, mesmo os grupos de apoio e de suporte não têm conseguido dar conta da demanda de sentimentos e perturbações vivenciadas pelas famílias atingidas por questões relacionadas à doença de seus familiares. O relato a seguir faz referência a essas considerações:

"... a doença mental é uma doença que abala toda a família, a família acaba tendo que se tratar junto... é uma coisa séria" (AFAGO).

A doença mental, devido a maneira como é referenciada por nossa sociedade, carrega em si a marca da cronificação e do preconceito. A vivência do adoecer da pessoa em sofrimento psíquico faz com que os familiares busquem os serviços de saúde mental, procurando entender o que seu ente querido está apresentando e comecem então a conviver com o diagnóstico médico. Por outro lado, os familiares encontram dificuldade para transmitir esse diagnóstico, levando-os a tentativas de descrição e explicação da doença que se rompe no meio da frase ou terminando com constatações de entendimento de acordo com suas próprias concepções, conforme evidencia o relato a seguir:

“... o prognóstico de doentes mentais novos é pior do que aqueles que apresentaram a doença aos 23 ou 24 anos. O nosso filho foi na adolescência, super novo .... tanto que o médico disse que o diagnóstico inicial era 'bifrênico', quer dizer, doença mental de novo" (AMOR).

Assim, percebemos que, na grande maioria das vezes, as explicações médicas acabam por cair num vazio para a família; tudo é nebuloso, o que causa a doença, onde a mesma está localizada e até o nome atribuido para a enfermidade. BASAGLIA (1985) afirma que, da forma como a psiquiatria tem rotulado $e$ classificado o sofrimento psíquico, não responde as necessidades de entendimento da família e esvazia o sentido do adoecer, ao basear-se apenas na sintomatologia apresentada, relegando a segundo plano a educação da família. O diagnóstico médico traz, ainda, como agravante, um prognóstico de conviver com a incurabilidade da enfermidade, ou seja, a família é obrigada a se conformar com a questão da cronicidade e se estruturar a partir dessa condição. $O$ relato a seguir testifica esse fator:

“... hoje eu sei que é uma doença, embora seja difícil admitir que é uma doença sem cura, que meu filho jamais irá ficar bom, que jamais poderá conviver comigo devido a seu comportamento conturbado" (AFAGO).

MORENO (2000) alerta para o fato de que concepções como esta se encontram impregnadas da psiquiatria tradicional. Para esta, o indivíduo com transtorno mental era um insano ou débil mental e sua cura tinha como significado a remissão total dos sintomas. Somente após a cura, poderia voltar a ser a pessoa que era antes de adoecer, poderia inserir-se na sociedade novamente, abandonando os porões da loucura. Numa nova abordagem da psiquiatria, não ocorrendo a remissão dos sintomas, a família, provavelmente, terá que aprender a conviver com um sujeito com possibilidades reduzidas de ter uma vida considerada normal, constituindo-se em ser cuidador desse sujeito e/ou afastar-se do mesmo, inserindo-o em modalidades de serviços substitutivos, como é o caso da moradia terapêutica. 
Diante disso, ROTELLI (1990) adverte quanto à necessidade de transformar o modelo de assistência às pessoas portadoras de transtorno mental, rompendo com o paradigma de solução-cura. $\mathrm{O}$ autor sugere uma busca de alternativas e possibilidades que devolvam a complexidade da existência a esse contingente de pessoas, por meio do respeito a singularidades de cada ser que procura os serviços de saúde, extensivo a seus familiares. Neste ínterim, aponta para estratégia de reabilitação psicossocial, entendida por SARACENO (1996, p. 16) como sendo "um processo de reconstrução, um exercício pleno da cidadania e, também, de plena contratualidade nos três grandes cenários: habitat, rede social e trabalho com valor social".

MARI et al (1999) mencionam que nem todos os familiares possuem condições estruturais, econômicas e emocionais para conduzir satisfatoriamente aspectos da convivência com a doença. De alguma forma, elaboram a experiência, lidam com seus sofrimentos e expectativas, podendo viabilizar a convivência com a doença, buscando apoio em tratamentos alternativos. Entretanto, é necessário ter-se o cuidado para não incorrer no erro de continuar com o estigma preconizado pela era clássica, de que "lugar de louco é no hospício" e que, portanto, o doente mental deve ficar distante de vínculos familiares, inserindo-o em seu próprio mundo. Se assim for, continuaríamos com a idéia obnubilada de que, para o cidadão portador de transtorno mental, não há possibilidades terapêuticas de interação.

Estudo realizado por ROLIN et al (2002) aponta que a ocorrência de uma patologia grave e de longa duração, como a doença mental, ativa uma série de respostas nas pessoas de seu grupo social, especialmente entre aquelas de seu convívio familiar. Entendemos que cada universo familiar tem sua história, seus padrões familiares distintos, sua identidade própria, sua forma de viver e proceder. Quando esses parâmetros são tolhidos em função de uma patologia que se instala em um de seus familiares, a família é abalada gerando uma cascata de sentimentos: o medo do imprevisível, a incerteza do amanhã, a tristeza e a angústia por não saber como lidar com uma situação nova imposta pela doença. MIRON et al (2002) pontuam que a doença mental, principalmente de caráter psicótico, desencadeia na família um processo de sofrimento intenso. Esses fatores relacionados podem ser vistos no depoimento de Afago mencionado anteriormente, em que ficam explícitas as repercussões da doença mental no seio da família.

Segundo MORENO (2000), a família é receptáculo da vida e também a célula básica da sociedade. Portanto, sofre os danos causados pela doença mental, principalmente por esta ser uma patologia com manifestações na esfera social. A fala a seguir contextualiza essas concepções: "... às vezes, a doença extrapola a capacidade dos próprios psicólogos e da família" (AFETO).

A Doença mental também foi vista, pelos participantes desta investigação, como sendo um mal endógeno.O depoimento a seguir traça um paradoxo entre a doença mental e a doença física: "... a doença mental não é como a doença física que tu olha e vê que a pessoa está com um problema, câncer, doença de pele, gripe" (AFAGO). Essa forma de compreensão da doença mental nos remete a idéia do adoecer psíquico como uma patologia diferenciada, que não mostra sinais evidentes de problemas orgânicos sendo, na maioria das vezes, explicado como sendo um mal endógeno. Na busca incessante de encontrar respostas para a doença, os familiares fazem verdadeira peregrinação às instituições de saúde, geralmente submetendo o doente a um emaranhado de exames, visando detectar onde está a doença e/ou procurando, assim, um "local no cérebro" que possa referenciar os desvios de comportamentos apresentados pela pessoa acometida de um transtorno mental. No entanto pesquisas indicam que não há um limite entre saúde e doença mental, já que a doença mental não é algo físico, mensurável, constatado em exames laboratoriais (WAIDMAN,1998).

Entendemos que o transtorno mental não se localiza em uma determinada região do cérebro que possa ser tratada focalmente, mas engloba, além do corpo biológico, uma série de outras áreas que, neste contexto, podem estar afetadas, a saber um ser biopsico-social, cuja existência se dá em suas múltiplas áreas de interação. Por outro lado, muitas vezes a tentativa de atribuir à enfermidade uma conotação biológica ocorre como forma de diminuir a culpa dos familiares.

Numa outra abordagem, a doença mental foi compreendida como sendo um mal dos nervos, como mostra a fala a seguir:

“... doença mental é qualquer transtorno dos nervos" (CARINHO).

Sabemos que esta é uma expressão inerente ao cotidiano popular, em que para um ser humano em situação de crise existencial é atribuído esse termo do senso comum. Nervoso é o termo utilizado para descrever uma ampla categoria de manifestações e situações geralmente vivenciadas por todas as pessoas em momentos de conflito ou tensão. O termo nervoso, além de ser usado como uma forma de expressão para os problemas cotidianos e conflitos familiares, reúne também um conjunto de aspectos estruturais e relacionais empregados por familiares para definir e compreender a doença mental (MARI et al, 1999). Desta forma, a definição da patologia como sendo um transtorno dos "nervos", surge como uma elaboração desta vivência por este familiar. 
Um aspecto fundamental da representação da doença como um problema de nervos é a nãodelimitação explícita como uma desordem que tem etiologia, sintomatologia e tratamento específico. Com esta situação, evitar-se-ia o emprego de terminologias mais estigmatizantes como, por exemplo, esquizofrenia. Dessa maneira, o problema é minimizado pois a classificação adotada o insere numa categoria que descreve situações mais brandas do processo de adoecer (MARI et al, 1999). Sendo a denominação "nervoso" uma entidade amplamente compartilhada e conhecida, elaboram-se também, a partir dessa compreensão, expectativas de recuperação e cura que, naturalmente, ficam mais limitadas dentro do modelo de patologias mais sérias como é o caso da esquizofrenia. Com o depoimento a seguir, notamos este aspecto implícito:

"... olha atualmente eu até acho que meu filho está bem, que até estamos cogitando que ele volte a ter uma vida normal" (CARINHO).

A doença mental ainda foi percebida como sendo um problema de caráter social. Ao analisarmos as linhas de abordagem que definem o binômio saúde/doença mental, percebemos que não existem limites fixos entre saúde e doença e talvez o critério para a enfermidade mental seja representado, em grande parte, pelo grau de comportamento diferente dos padronizados (WAIDMAN, 1998). Nesta ótica, para ser considerado saudável e normal, o sujeito deve apresentar um comportamento próprio que confirme e caracterize sua identidade, deve ter um projeto de vida idealizado, senso de autonomia pessoal e boa vontade, ser capaz de manter boas relações sociais e vínculos familiares adequados, ser útil em alguma esfera profissional, enfim ter e manter a integridade da ordem estabelecida, considerada nas suas mais variadas dimensões - morais, sociais, econômicas, políticas, culturais etc. Se, por outro lado, o indivíduo exceder às regras e normas socialmente estabelecidas, logo é taxado como anormal, como um louco, insano, um conturbado das faculdades mentais. A família acaba incorporando esses conceitos estigmatizadores, evidenciado pela fala a seguir:

“...em função dos sintomas de seu problema, de seu comportamento eu acho que ele não pode ser considerado uma pessoa normal... até mesmo em função dos medicamentos que ele toma, qualquer pessoa vê que ele não está em seu estado normal" (CARINHO).

Por outro lado percebemos que essa é uma forma de conceber a doença mental no seu aspecto tradicional que, conforme muito bem abordou DONATO (1999, p. 14), "é supostamente possível designar como louco tudo aquilo que não parece corresponder a imagem que a razão tem dela mesma".
Essa posição na era do classicismo era muito cômoda para os "normais", pois podiam contar com o hospício como uma lata de lixo psicológico, onde se permitia projetar suas partes loucas, fazendo-as se sentir sãs (HUMEREZ,1996).

Considerando aspectos históricos da doença mental, percebemos que esta sempre foi vista como uma característica dos "anormais", repleta de preconceitos e estigmas de toda a ordem, principalmente em relação a uso de fármacos psicotrópicos, o que se evidencia na citação de CARINHO acima mencionada. Por outro lado, percebemos que esta é uma crença que foi responsável pelo abandono de muitos doentes mentais em instituições como os manicômios. No entanto, entendemos que a patologia mental possui um caráter crônico como outra qualquer e, nem por isso, o indivíduo portador desse transtorno deve ser considerado um inútil ou um "louco" improdutivo. Desde que faça o tratamento adequado e realize os cuidados necessários, poderá ter uma vida próxima do "normal" idealizado.

Em conversa informal registrada no diário de campo, AFAGO revela que seus amigos interrogam sobre o estado de saúde de seu filho da seguinte maneira:

“... aquele que enlouqueceu". O mesmo dá o seguinte depoimento: “... isso me deixa muito triste, mas ... tento manter a calma e explicar que não, que o que meu filho apresenta é uma doença" (AFAGO).

Ainda AFAGO, no mesmo depoimento, afirma:

“... a doença mental é uma doença que causa medo, pavor em quem com ela convive".

Esse fato evidencia mais uma vez a questão do preconceito em relação a uma pessoa acometida de um problema mental, preconceito este ainda muito presente em nossos dias, mesmo diante de toda as mudanças ocorridas nesta área da saúde. Esse é um fator desencadeante de estresse para a família que apresenta em sua célula um doente mental, tornandose uma rotina de sofrimento intenso. Neste ínterim, é reforçada a necessidade de dar continuidade à conscientização da sociedade frente a estes transtornos, evitando a rotulação da pessoa e facilitando a compreensão da doença.

Nesta mesma linha de abordagem, o depoimento a seguir indaga questões relativas a padrões de normalidade:

“... a doença mental é acima de tudo um problema social, mais do que o doente em si o problema está do lado de fora, em como as pessoas ditas normais encaram isso aí... muitas vezes quem está do lado de fora e se diz normal é muito mais louco do que quem está internado" (DEDICAÇÃO). 
Esta depoente percebe a doença mental como algo que fere os padrões considerados "normais" pela sociedade. Podemos apreender que esta concepção é perpassada pelo paradigma da psiquiatria clássica, em que tal definição de doença mental tem, em sua gênese, um sujeito sem "razão".

Para ENGEL (1999), a psiquiatria consolida-se e institucionaliza-se, no Brasil, como um campo de conhecimento especializado a partir do século passado caracterizando-se entre outros aspectos, pela incorporação de uma ampla variedade de temas, fixando as fronteiras que separariam a "doença" da "saúde", o "normal" do "patológico", no âmbito dos distúrbios mentais. Entre os temas privilegiados pelos psiquiatras brasileiros na construção de atos, atitudes, hábitos, comportamentos, crenças e valores 'desviantes', figuravam, por exemplo, a civilização, a raça, a sexualidade, o trabalho, o alcoolismo, a delinqüência, criminalidade, o fanatismo religioso e a contestação política. Segundo a autora, estes temas eram fundamentais para conferir limites extremamente abrangentes à noção de 'anormalidade'. Desse modo, os focos de ameaça a integridade da ordem seriam identificados e/ou associados à loucura. Nesse viés, a loucura era vista como "o avesso da ordem, sinônimo de agitação, exagero, desregramento, impulsividade, imprevisibilidade e periculosidade" (ENGEL, 1999, p. 2). $\mathrm{Na}$ contemporaneidade, percebemos que ainda restam resquícios destas percepções como subversão/inversão das normas e regras socialmente estabelecidas e a família passa a ser a parte mais afetada pelos reflexos da doença mental tanto no plano familiar como no social.

Para alguns depoentes, a doença mental foi citada como sinônimo de incapacidade. Esta forma de perceber a doença mental foi expressa por alguns familiares entrevistados. Citaremos aqui apenas um relato:

". .tem aproximadamente 17 anos que meu filho sofre com este problema incapacitante da esquizofrenia" (AMOR)

Nesse depoimento, o informante não deixa claro qual o tipo de incapacidade presente no seu familiar doente mental. Estudos realizados apontam para a idéia de que uma característica do comportamento do doente mental, em especial aquele portador de patologia de caráter psicótico, é o déficit de interesse e capacidade no que concerne ao autocuidado e realização de atividades qüotidianas. Esse déficit, que tem um grau de variabilidade entre os doentes, acaba sendo interpretado indistintamente como incapacidade (BERTOLLO, 2003).

Por outro lado, a concepção de incapacidade atribuída aos doentes psicóticos crônicos, praticamente, fecha as portas do mercado de trabalho para eles, pois o doente mental é visto pela sociedade como um ser improdutivo e, portanto, não tendo direito de convívio familiar e nem direitos e deveres de cidadão (OLIVEIRA \& JORGE, 1998). O relato a seguir expressa um pouco dessa concepção: "....ele parecia uma pessoa normal aparentemente, tinha família, emprego, mas isso não durou muito, pois todo mundo o chamava de doido, que fosse se tratar " (CARINHO).

Essa forma de pensar e de proceder é típica de uma sociedade capitalista, em que prevalece a conotação do indivíduo enquanto "força de trabalho" e não como ser humano, dotado de singularidades e de limitações físicas e/ou psíquicas que o impedem de produzir. Numa sociedade como esta, a cidadania é um atributo dos 'iguais', dos 'normais', dos que podem decidir de forma convencional. Defendemos a idéia de que os ditos 'diferentes', os 'bizarros', os 'estranhos' também devem ter seus direitos garantidos, prevalecendo a eqüidade. As mudanças devem começar no seio familiar, pois notamos que, muitas vezes, os estigmas e preconceitos partem da própria família.

Por fim a doença mental foi mencionada como uma situação de desrealização e despersonalização. A fala a seguir nos revela a amplitude que um transtorno psicótico pode atingir na fase de agudização dos sintomas:

"... acho que ser doente mental é ficar fora da realidade, se transformar em uma outra pessoa ... ele me desconheceu na hora do surto, ficou totalmente transformado, não era ele, era outra pessoa, não era ele" (TERNURA).

A literatura descreve a psicose como sendo um comprometimento grave do funcionamento mental, social e pessoal, manifestado pela perda do teste de realidade, retraimento social, incapacidade para desempenhar os papéis ocupacionais e domésticos habituais. Soma-se a isso a ocorrência de delírios, alucinações e confusão de toda ordem, sem discernimento de sua natureza patológica (KAPLAN et al, 2003). Na psicose temos em jogo dois pólos distintos: a despersonalização e a desrealização (LOPES, 2001). Para o autor, "a psicose é formada por um conjunto de alterações do conhecimento do indivíduo do próprio eu e do conhecimento do indivíduo do mundo em que ele se encontra. Desta forma ocorre a perda do próprio eu, este eu que se transforma, que se modifica, que chega até ao apagamento total da relação com o mundo exterior, que se torna agressivo, que se torna diferente, ameaçador, perseguidor e por vezes melancólico, apagado, triste, ou ainda que se torna num carnaval de manias" (LOPES, 2001 p. 4).

Esta forma de perceber patologias psiquiátricas como desrealização e despersonalização se deve ao fato de que, realmente nos sintomas agudos da doença, o paciente perde o teste de realidade e de percepção de seu próprio eu. Conforme muito bem 
pontua LOPES (2001), "para patologias psicóticas em seus picos agudos podemos atribuir ao fenômeno aquele mais velho e conhecido nome loucura". Mas entendemos que nem por isso o portador de patologias desta categoria deve ser um enjeitado ou submetido a condição de indigente. Ao invés disso, é nestas horas que os familiares devem ser orientados quando ao estado de saúde de seu familiar e assistidos em todas suas necessidades. Nesses aspectos, surge também a exigência de conscientização da sociedade frente a estes transtornos, evitando a rotulação deste doente e facilitando a compreensão deste fenômeno pela população em geral.

Num outro contexto e para muito além dessa abordagem estigmatizante do doente mental, encontramos famílias bem alicerçadas que demonstram compreender a condição de saúde a que seu familiar está submetido, conforme vemos a seguir:

"... é necessário tentar entender o filho, ou seja lá quem for, entendê-lo como um doente e não como um preguiçoso, um agressivo porque quer ser agressivo, não, é porque realmente a doença é avassaladora para o próprio doente e ele reage assim" (AMOR).

Desta forma, percebemos a necessidade de esclarecimento aos familiares e a própria sociedade, desmistificando distintas concepções errôneas no que diz respeito ao doente mental e suas capacidades. WAIDMAN (1998) pontua que os familiares necessitam de esclarecimentos referente a patologias crônicas, bem como orientações sobre o relacionamento com o doente no espaço domiciliar e como enfrentar problemas sociais e econômicos advindos desta experiência. Se assim ocorrer, certamente os familiares estarão melhor informados e passariam a ser protagonistas do processo de reinserção e reabilitação psicossocial do doente mental, algo a ser ainda conquistado no âmbito dos equipamentos que tratam da saúde mental.

\section{CONCLUSÃO}

Considerando o relato contextualizado dos familiares, após a análise, é possível fazer alguns apontamentos. Primeiramente, reportando-nos ao pressuposto acima referenciado, chegamos a conclusão de que ainda hoje, mesmo diante de toda transformação dos paradigmas da saúde mental preconizados pela Reforma Psiquiátrica, é possível encontrarmos na sociedade e nela insere-se a família, resquícios de concepções da doença mental de caráter psicótico como aquele mais velho fenômeno de todos, a loucura. Ao analisar os relatos e principalmente por meio das anotações do diário de campo, por vezes, chegamos a pensar definitivamente que, para a sociedade em geral, psicose é igual a loucura. Essa loucura não diverge muito daquela que foi responsável pelo abandono de milhares de pessoas em porões imundos na era clássica. Enfim, mudou-se apenas a abordagem, a forma de tratamento e de encarar tal situação, mas a concepção, em muitas situações permanece inalterada.

Assim, percebemos que a história da loucura pode ser interpretada como a história de sua representação. A evolução da psiquiatria e da assistência prestada ao doente mental indica que a cada modalidade terapêutica proposta, a cada atitude definida diante da doença mental, a cada diagnóstico formulado nos serviços de psiquiatria, esteve sempre subjacente uma forma de representação da doença, como expressão das interpretações hegemônicas que circulam no imaginário social. A verdade a que chegamos é que a doença mental e/ou a loucura sempre foi um fenômeno social interpretado, representado e tratado de diversas maneiras, de acordo com o contexto e o momento histórico vivido. Esses princípios podem ser vistos na prática e por meio da literatura, as quais expressam os paradoxos atribuídos a doença mental no decorrer dos tempos.

Por muito tempo, coube ao hospício legitimar suas ações sobre a loucura, separando o portador de transtornos mentais da família para "melhor reorganizá-lo". Hoje estamos diante de uma nova lógica a orientar a atenção ao doente mental, ou seja, a lógica da inclusão. Temos como premissa que a doença mental deve ser compreendida como um fenômeno complexo e histórico, atravessado pelas dimensões psicossociais, capazes de determinar o binônimo saúde-doença mental. Neste contexto, pudemos presenciar, nos últimos anos, a proliferação de uma vasta variedade de serviços substitutivos de atenção a saúde mental. Estes serviços se propõem a oferecer um espaço de atendimento que atue pelo viés do cuidado emglobando a equipe de profissionais, usuários e familiares, atentando para os efeitos institucionalizadores desta ação, tendo como alvo a completa reinserção do doente no meio social, a partir da reabilitação.

Por outro lado, percebemos que, mesmo dentro de um determinado padrão cultural, existem elementos de variação e complexidade de conceitos da doença, denotando categorias ambíguas e amplas no meio popular. Assim identificamos concepções de doença mental que ora são apresentadas como sendo efeito de fatores biológicos ou psicossociais, ora é encarada como sendo um mal dos nervos ou da cabeça, ora é vista como perda do padrão da normalidade e/ou ainda como sendo fruto das características sociais, entre outras. Pensamos que, muitas vezes, esta ambigüidade de concepções torna-se uma estratégia para lidar com a realidade de uma condição mórbida que assume formas variadas e evolui, sem padrão previsível. Fato é que os familiares aqui referenciados atribuem a doença mental uma complexidade de fatores e de concepções diferenciadas e hegemônicas. 
Com isso, nos questionamos como está sendo desenvolvido o saber-fazer em psiquiatria. A idéia não é que todos indistintamente deveriam ter as mesmas referências em suas concepções, mas que pelo menos houvesse um entendimento com maior embasamento científico, uma vez que a grande maioria dos sujeitos, cujos familiares participaram desta investigação, convive com a patologia há bastante tempo e são pessoas com um nível cultural diferenciado. O que percebemos, no entanto, é que há na estrutura do adoecer dois pólos distintos: um caracterizado pela visão dos usuários e familiares e outro pelos profissionais, gerando, por vezes, uma dicotonomia de saberes, cuja base implica numa ruptura entre o senso comum e o conhecimento científico.

Outra questão que nos chama a atenção é que, passadas duas décadas do início da Reforma Psiquiátrica, podemos ainda observar um forte estigma vinculado a doença mental. Sabemos das repercussões principalmente de caráter social advinda desta prática, tanto no seio familiar como para o próprio sujeito que sofre os danos do preconceito e da discriminação. Sabemos também que as repercussões da doença mental de caráter psicótico em sua fase aguda são altamente danosas e assustadoras, dada a complexidade de sintomas apresentados. $E$ é justamente na vivência da fase aguda, que, muitas vezes os familiares ou demais pessoas que presenciam tal situação, acabam rotulando o doente mental de "louco". O que precisamos, enquanto profissionais de saúde, é entender e ajudar os familiares a compreender que a "loucura" e/ou a doença mental são manifestações da pessoa e que ela precisa de ajuda.

Neste ínterim, emerge a necessidade de inserir a família na consolidação do processo de desinstitucionalização, por meio de duas opções: o doente continuar convivendo diariamente com a família, em que esta passará ao papel de cuidador e ainda que o doente habite em residências assistidas, quando os familiares não conseguem conviver diretamente com o familiar enfermo, ocorrendo contatos esporádicos com os mesmos de forma a evitar prejuízo no relacionamento familiar. Mas, cabe salientar que, neste novo cenário instituído pela Reforma Psiquiátrica, a saber as moradias terapêuticas, todo o cuidado deve ser direcionado para que o trabalho ali realizado seja realmente em prol do cidadão doente, na garantia de seus direitos e na busca incessante de fazer desta pessoa um ser humano digno e respeitado. Para tanto, não basta trancafiar a pessoa dentro de uma residência, mas proporcionar-Ihe modalidades terapêuticas capazes de garantir-lhe liberdade de ação, para que ele possa extravasar suas criatividades por meio de terapias ocupacionais, em que ele possa ser útil, envolvendose em atividades domésticas, laborais, recreativas, de lazer e de autocuidado e, ainda, desenvolver práticas comunitárias e de socialização. Somente assim poderíamos afirmar que realmente a reabilitação psicossocial direcionada ao doente mental está tendo e fazendo sentido.

Assim ao concluir esta retórica, reafirmamos o quanto é necessário desmistificar concepções minadas de estigma sobre a doença mental e acima de tudo reiteramos a necessidade de atender as pessoas com transtornos psicóticos por meio de uma assistência qualificada e humanizada. Pensamos que aí está o grande impasse na melhora da qualidade de vida a esse contingente populacional. Encerramos o texto por meio de uma fala de uma das familiares entrevistadas:

"Do mais, do pouco que tenho de conhecimento, o cérebro ainda é um mistério, mas eu acho que a gente, como ser humano e com amor, poderemos melhorar a qualidade de vida dessas pessoas..." (DEDICAÇÃO).

\section{REFERÊNCIAS BIBLIOGRÁFICAS}

BASAGLIA, F. As instituições da violência. In: BASAGLIA, F. A instituição negada. Rio de Janeiro, Graal, 1985. p. 99-133.

BERTOlLO, E. Convivência de Familiares com Doentes Mentais Psicóticos, Egressos de Hospitais Psiquiátricos. ljuí: UNIJUI, 2003, 98p. Monografia (Graduação em Enfermagem), Universidade Regional do Noroeste do Estado do Rio Grande do Sul.

BRASIL, Conselho Nacional da Saúde. Resolução 196/96. Trata das Diretrizes e Normas Regulamentadoras de Pesquisa envolvendo Seres Humanos. Brasília, 1996.

DONATO, S. Uma Leitura de Foucault: A história da Loucura na Idade Clássica. Ijuí: Ed. UNIJUI, 1999. Monografia (Graduação em Filosofia), Universidade Regional do Noroeste do Estado do Rio Grande do Sul.

ENGEL, M. G. As fronteiras da 'anormalidade': psiquiatria e controle social. História, Ciências e Saúde. Manguinhos, v. 5, n.3, p.547-563, Fev 1999.

GIL, A. C. Métodos e Técnicas de Pesquisa Social. 5. ed., São Paulo: Editora Atlas, 1999.

HUMEREZ, D. C. de. Em Busca de Lugares Perdidos: Assistência ao Doente Mental revelada através das histórias de vida. São Paulo: USP, 1996. p. 220. Tese (Doutorado) Escola de Enfermagem da Universidade de São Paulo.

INSTITUTO CYRO MARTINS. Material informativo. 2004. /Digitado/.

KAPLAN, H. I.; SADOCK, B. J.; GREBB, J. A. Compêndio de psiquiatria: ciências do comportamento e psiquiatria clínica. 8 ed. Porto Alegre: Artes Médicas, 2003.

KOGA, M.; FUREGATO, A.R. Convivência com a pessoa Esquizofrênica: sobrecarga familiar. IN: 
LABATE R.C. (Org.). Caminhando para a assistência integral. Ribeirão Preto: SCALA, 1998, p.363-377.

LOPES, J. L. A psiquiatria na época de Freud: evolução do conceito de psicose em psiquiatria. Revista Brasileira de Psiquiatria; v. 23, n.1, p.28-33, Mar 2001.

MARI, J.; VILLARES,C. C.; REDKO,C. P.Concepções de doença por familiares de pacientes com diagnóstico de esquizofrenia. Revista Brasileira de Psiquiatria. v.21, n. 1, p.36-47, mar 1999.

MINAYO, M.C.S. Pesquisa social: Teoria, método e criatividade. 19 ed. Petrópolis: Vozes, 2001.

MIRON, V. L.; et al. A assistência à saúde mental em um sistema local na ótica de familiares. IN: SAEKI, T.; SOUZA, M.C.B. de M. (org). Cuidar: tão longe tão perto. Ribeirão Preto: Maxicolor e Gráfica, 2002, p.195-210.

MORENO, V. Vivência do Familiar da Pessoa em Sofrimento Psíquico. 2000. p. 173. Tese (Doutorado), Escolas de Enfermagem de Ribeirão Preto da Universidade de São Paulo.

OLIVEIRA, M. M.B; JORGE, M.S.B. Doente Mental e sua relação com a família. In: Labate R.C. (Org.) Caminhando para a assistência integral. Ribeirão Preto: Scala, 1998, p. 379-388.

ROLIN, M. A.; IDE, C. A; COLVERO, L. de A.; C. Família e Doença Mental: a difícil convivência com a diferença. Revista da Escola de Enfermagem da USP. v.38, p. 197- 205, fev.2002.

ROTELLI, F. A Instituição inventada. In: Nicácio, F. (org). Desinstitucionalização. São Paulo, Hucitec, 1990, p.89-99.

SARACENO, B. Reabilitação psicossocial: uma estratégia para a passagem do milênio. In: PITTA, A. Reabilitação Psicossocial no Brasil. São Paulo: Hucitec, 1996.

STUART, G. W.; LARAIA, M. T. Enfermagem psiquiátrica: Princípios e prática. 6. ed. Porto Alegre: Artmed, 2001.

TAYLOR, C. M. Fundamentos de Enfermagem Psiquiátrica de Mereness. 13. ed. Porto Alegre: Artes Médicas, 1992.

TOWNSEND, M. C. Enfermagem Psiquiátrica: conceitos de cuidados. 3. ed. Rio de Janeiro: Guanabara Koogan, 2002.

TRIVINOS, A. N. Introdução à Pesquisa em Ciências Sociais. São Paulo: Atlas, 1999.

WAIDMAN, M. A. P. Enfermeira e Família Compartilhando o Processo de Reinserção Social do Doente Mental. Curitiba: UFSC, 1998. p. 114. Dissertação (Mestrado), Curso de Mestrado em Assistência de Enfermagem, Universidade Federal de Santa Catarina- REPENSUL - POLO 1 - Universidade Federal do Paraná - UFPR.
Texto recebido para publicação em 23/08/2005 Publicação aprovada em 30/08/2005 